\title{
Value and moral component of the concept «future» in Russian linguoculture
}

\author{
A. G. Stolyarova ${ }^{1}$
}

1Pushkin State Russian Language Institute, 6 Acad. Valgin Str., Moscow 117485, Russian Federation

DOI: $10.18255 / 2412-6519-2020-2-196-204$

Research Article

Full text in Russian

The paper deals with culture generating texts treated as speech products corresponding to dominant features of civilization in cultural history. Three types of such texts - sacral regulations, mass circulation products and virtual net messages - have radically changed the idea of authorship and corresponding attitudes of public to texts. The first text type brought to life selected priests who were regarded as keepers of sacral knowledge to be transmitted to coming generations, the second text type initiated numerous artisans who produced various one-time texts suitable for everyday purposes, the third text type generated illusionists who launch secondary texts through the world electronic network for the sake of carnival play with life. The characteristics of three types of text as indicators of culture have been described on the material of aphorisms. Autosemantic sentences of the first type are usually expressed as manifestations of general truth or common norms of behavior, the second type phrases function as trivial observations or specific recommendations in particular situations, whereas the third type texts have a paradoxical nature or are used as banter expressions uttered to fill the gaps in conversation. Sentences of the first type make the core golden reserve of human wisdom, and they are often used in situations of social inequality when people demonstrate their experience and right to give lessons to others. Sentences of the second type are very important for everyday routine life, and they appear in corresponding habitual situations. Sentences of the third type are applied mainly in interactions which require a critical reaction to any type of edification, either moral or utilitarian, their aim is to establish equality as such by means of ridicule of any kind of self-admiration.

Keywords: culture; text; discourse; genre; authorship; carnival; aphorisms

\section{INFORMATION ABOUT THE AUTHORS}

$$
\begin{array}{l|l}
\text { Stolyarova Alexandra G. } & \begin{array}{l}
\text { E-mail: aleks-stolyarova@yandex.ru } \\
\text { Candidate of Sciences in Philology degree seeking applicant }
\end{array}
\end{array}
$$

For citation: Stolyarova A. G. Value and moral component of the concept «future» in Russian linguoculture // Social'nye i gumanitarnye znanija. 2020. Vol. 6, No 2. P. 196-204. (in Russ.)

(C) Stolyarova A. G., 2020

This is an open access article under the CC BY-NC-ND license (http://creativecommons.org/licenses/by-nc-nd/4.0/) 


\title{
Ценностно-нравственный \\ компонент концепта «будущее» \\ в русской лингвокультуре
}

\author{
А. Г. Столярова ${ }^{1}$
}

1Государственный институт русского языка имени А. С. Пушкина, ул. Академика Валгина, 6, Москва, 117485, Российская Федерация

DOI: 10.18255/2412-6519-2020-2-196-204

УДК 811.161 .1

Научная статья

Полный текст на русском языке

Интерес исследователей к концептам - «сгусткам» человеческой культуры - не ослабевает по сей день, о чем свидетельствует большое количество работ, посвящённых концептуальному анализу в рамках лингвокультурологии, когнитивной лингвистики, сопоставительного лингвострановедения, этнолингвистики, этнопсихолингвистики и др. Несмотря на это, все еще невозможно говорить об исчерпывающем описании концептосферы той или иной (в частности, русской) лингвокультуры, что заставляет автора настоящей статьи обратиться к означенной выше теме и задаться целью описать не исследованный ранее в отечественной науке концепт «будущее». Автор обращается к предложенной О. А. Корниловым методике разделения обыденного сознания на 4 уровня (сенсорно-чувственный, логико-понятийный, эмоционально-оценочный и ценностно-нравственный) и на материале паремического фонда русского языка анализирует ценностно-нравственный компонент концепта, выделяя в нем 15 сем, различные комбинации которых образуют несколько групп поведенческих норм. Результаты концептуального анализа проецируются на грамматику. Параллели с грамматическими значениями будущего времени в русском языке позволяют автору предположить наличие связи между грамматикой и содержанием концепта. Очерчивается сфера возможного применения результатов исследования в смежных с лингвокультурологией областях науки.

Ключевые слова: лингвокультурология, концепт «будущее», концептуальный анализ, ценностно-нравственный компонент концепта, граммема будущего времени, грамматическое значение

ИНФОРМАЦИЯ ОБ АВТОРАХ

Столярова Александра Георгиевна

Email: aleks-stolyarova@yandex.ru

Соискатель ученой степени кандидата филологических наук кафедры русской словесности и межкультурной коммуникации

Для цитирования: Столярова А. Г. Ценностно-нравственный компонент концепта «будущее» в русской лингвокультуре // Социальные и гуманитарные знания. 2020. Том 6, № 2. С. 196-204.

(C) Столярова А. Г.., 2020

Статья открытого доступа под лицензией СC BY-NC-ND (http://creativecommons.org/licenses/by-nc-nd/4.0/) 


\section{Введение. Концепт «будущее» как предмет лингвокультурного концептуального анализа}

В лингвокультурологии время неоднократно становилось предметом концептуальных исследований. Постижению времени через язык посвящены, например, сборник «Логический анализ языка. Язык и время» под ред. Н. Д. Арутюновой [1], работы Л. Н. Михеевой [2], Т. А. Обуховой [3] и др. Время в этих работах не расчленяется на составляющие и рассматривается в единстве своих модусов - прошлого, настоящего и будущего. Однако, взятое как самостоятельный концепт, «будущее» оказывается шире и содержательно богаче, нежели просто составная часть концепта «время», поэтому мы полагаем необоснованным считать его лишь «частным» [4, с. 210], «гипонимическим» концептом по отношению к «гиперониму» «время». По нашему мнению, его содержательное поле частично накладывается на поле концепта «время», но одновременно - распространяется и за его пределы. Согласно нашим наблюдениям, на фоне неоднократно описанного концепта «время» культурный концепт «будущее» остается неразработанным и требует отдельного исследования, что обусловливает актуальность настоящей статьи, в структуре которой ставятся и решаются задачи определения методики описания будущего как лингвокультурного концепта, анализа концепта «будущее» в русской лингвокультуре, установления связи его характеристик с грамматическими значениями форм будущего времени в русском языке.

\section{Метод анализа лингвокультурного концепта}

Теоретической основой концептуального анализа стали работы В. И. Карасика и О. А. Корнилова. Так, мы согласны с мнением В. И. Карасика, что культурный концепт представляет собой трёхчастную структуру, в которую входят образный, понятийный и ценностный компоненты [5]. Однако, на наш взгляд, описанные структурные компоненты концепта с точки зрения лингвокультурного подхода нельзя считать равноценными. Руководствуясь определением культуры П. А. Сорокина, согласно которому культура являет собой совокупность значений, ценностей и норм, передаваемых из поколения в поколение [6], мы считаем доминантой лингвокультурного концептуального анализа выявление и описание ценностного компонента концепта. Ценности как таковые не поддаются описанию лишь на основании собственных ощущений и переживаний, поэтому наиболее релевантным при научном исследовании оказывается их определение через оценки и поведенческие нормы, зафиксированные в коннотативных значениях и внутренней форме слов, фразеологизмах, пословицах и поговорках, культурных текстах и др. В связи с этим представляется продуктивным алгоритм анализа концепта, соответствующий описанной О. А. Корниловым [7] структуре обыденного сознания и включающий в себя анализ сенсорно-рецептивного, логико-понятийного, эмоционально-оценочного и ценностно-нравственного компонентов концепта. Разделение ценностного компонента на эмоционально-оценочный и ценностно-нравственный не является случайным. Оценки, формируемые в эмоционально-оценочном компоненте сознания (оценки 1 уровня), - это простейшие оценки, которые «непосредственно фиксируют именно эмоциональное отношение коллективного носителя языка к обозначае- 
мому» [Там же. С. 231] и реализуются в бинарной оппозиции «положительное отношение - отрицательное отношение». Ценностно-нравственный компонент сознания порождает более сложные оценки (оценки 2 уровня), которые применяются «по отношению к наиболее типичным социально значимым ситуациям, моделям поведения в таких ситуациях, по отношению к жизненно важным для любого социума категориям» [Там же. С. 232]. Эти оценки, которые обычно находят выражение в виде пословиц и поговорок, обобщают коллективный жизненный опыт, имеют сложную логическую структуру, указывают на связи между явлениями, причинно-следственные связи, предписанный порядок действий в определенных ситуациях, ценностную иерархию общества, обобщают поведенческие нормы языкового коллектива. Именно выявление и анализ оценок 2 уровня в русском культурном концепте «будущее» является целью настоящего исследования. В основу данной процедуры мы кладём принцип семной организации концепта.

\section{Ценностно-нравственный компонент концепта «будущее». Анализ паремий о будущем}

С помощью паремиологического словаря В. И. Зимина [8] и свободного поиска в сети Интернет мы выделили пословицы и поговорки, реализующие те или иные семантические компоненты концепта «будущее».

Самую большую группу паремий организует вокруг себя сема 1 'то, то неизвестно, неопределенно'. Пословицы и поговорки с данной семой, как правило, содержат также сему 2 'события, ситуации' и в самом общем смысле выражают идею, что о действиях и событиях будущего нельзя знать наверняка: (Наперёд) не угадаешь, где найдёшь, где потеряешь; (Наперёд) не угадаешь, кому по ком плакать; (Наперёд) не угадаешь, где упадёшь, где встанешь; Это ещё по воде вилами писано; Знать бы, где пасть, так соломки бы подостлать; К весне - куда хлестнёт; Утро вечера мудренее; Будет день - будет и пища; Цыплят по осени считают; Не ровён час, всякое может случиться. Неопределённость будущего подчёркивается с помощью указания на изменения, которые неизбежно несёт с собой время (сема 3 'время'): чем больше времени отделяет настоящий момент от подразумеваемого момента в будущем, тем менее определёнными являются будущие события (Ещё до той поры много воды утечёm).

Будущее станет известным, когда человек сможет наблюдать его лично (сема 4 'то, что можно увидеть'), т. е. когда будущее станет настоящим, и этого момента надо лишь дождаться (сема 5 'то, чего ждут, и то, что ожидает'): Поживём - увидим; Поживёшь подольше - увидишь побольше; Поживёшь с наше - ещё не то увидишь (сема 6 'жизнь'); Что было, видели деды, что будет, увидят внуки; Там видно будет; Война план покажет; Слепой сказал: «Посмотрим!».

События будущего неизвестны еще и потому, что зависят не только от действий человека, но и от воли высших сил. Сочетание «сема 1 + сема 2 + сема 7 'то, что зависит от воли высших сил'» указывает на связь концепта «будущее» с одной из ключевых идей русской лингвокультуры - идеей непредсказуемости мира [9], которая представляет собой установку на принципиальную невозможность не только предугадать события, но и повлиять на них. Сознанием русского человека владеет мысль, что миром управляют неподвластные ему силы, делающие жизнь и будущее 
неподконтрольными его усилиям. Будущее приходит как объективный факт (Вчера не догонишь, а от завтра не уйдёшь; Жили люди до нас, будут жить и после нас) и создаётся тем, что сильнее нас, следовательно, нам остаётся только принять его: Человек предполагает, а Бог располагает (сема $\left.7(+)^{1}\right)$; Бог даст - сделаем (сема 7(+)); Так не будет, а уж как-нибудь, да будет (сема 7(+)); Дай Бог справиться, и нам будут кланяться (сема 7(+)); Хочешь рассмешить Бога - расскажи ему о своих планах (сема $7(0)$ ). В целом данная паремическая группа предписывает отказ от попыток предполагать и прогнозировать будущее и даже вводит прямой запрет на высказывание категоричных суждений о нем: Когда говорят о будущем, на чердаке мыши смеются; О будущем говорить - чертей смешить; Загад не бывает (не живёт) богат; На будущее не зарекайся; Наперёд не загадывай; Не загадывай в год, а загадывай в рот; Рано пташечка запела, кабы кошечка не съела.

Не следует раньше времени говорить об успехе (сема 8 'ожидаемый успех, удача'), так как он не гарантирован: Не говори «гоп!», пока не перепрыгнешь; Хвали день по вечеру; Вечер покажет, каков был день; Хвали утро вечером; Хвали день по вечеру, а жизнь - по смерти; Хвались урожаем, когда зерно в закрома ссыпешь; Не верь гречихе в цвету, а верь в закрому; Не хвались, в поле едучи, хвались, с поля везучи; Не поймал, да ощипал; Не дели шкуру неубитого медведя и др. Кроме того, такие паремии, как Утро вечера мудренее; Будет день - будет и пища; Цыплят по осени считают; Поживём - увидим; Там видно будет; Война план покажет; Рыба в реке не в руке и т. п., призывают не действовать слепо по заранее намеченному плану, а уметь ориентироваться в изменяющихся обстоятельствах.

Неизвестность как ключевая характеристика плана будущего тесно связана с пониманием того, что будущее представляет собой спектр возможных вариантов развития событий (сема 9): Бабка ворожила, да надвое положила; Бабка надвое сказала: то ли дождик, то ли снег; То ли дождик, то ли снег, то ли будет, то ли нет; Ни от сумы, ни от тюрьмы не отрекайся; На всякий час не обережёшься; Может случиться, что и богатый к бедному постучится. Возможные события и состояния (сема 2, сема 10 'состояние, положение') могут осмысляться как нежелательные, опасные (сема 11 'то, что подвергается оценке, осмыслению, эмоциональному переживанию’(-)). В этом случае пословицы призывают предугадывать, предусматривать наихудший вариант будущего и по возможности готовиться к нему: Не избывай постылого, приберёт Бог милого; Живи надвое: и до веку, и до вечеру; Ешь на день, хлеба бери на наделю; Бережёного (u) Бог бережёт; Искру туши до пожара, беду отводи до удара; В дождь крышу не кроют, а в вёдро сама не течёт (с иронией); Не суйся в воду, не изведав броду; Береги денежку про чёрный день; Берегись бед, пока их нет; Жить надейся, а умирать готовься и др.

Легкомысленное поведение, нежелание предусматривать риски, надежда на авось, на высшие силы, на то, что все устроится само собой (сема $7(-))$, наоборот, оцениваются отрицательно: Авось - дурак, с головой выдаст; Авось да как-нибудь до добра не доведут; Авось и рыбака толкает под бока; Авоська верёвку вьет, небоська петлю закидывает; Авоськал, авоськал, да и доавоськался; Русский человек на трёх сваях стоит: авось, небось да как-нибудь; Бог-то Бог, да сам не будь плох; На Бога надейся, да сам не плошай; На авось полагаться - без головы остаться и др.

\footnotetext{
${ }^{1}$ Здесь и далее: (+) - положительная оценка; (0) - отсутствие оценки; (-) - отрицательная оценка.
} 
В некоторых случаях способность идти на риск (возможность, оцениваемая отрицательно: сема 9 + сема 11(-)) может получать положительную оценку - как смелость и умение без долгих обдумываний предпринимать решительные действия в условиях неизвестности, когда одинаково возможны как благоприятный, так и наихудший варианты развития событий: Риск - благородное дело; Смелость города берёт; Или пан, или пропал; Или полковник, или покойник; Или с крестом, или под крестом; Или грудь в крестах, или голова в кустах; Либо в стремя ногой, либо в пень головой; Либо мёд пить, либо биту быть; Либо сена клок, либо вилы в бок; Пропадай моя телега, все четыре колеса! Двум смертям не бывать, а одной не миновать и др.

Несмотря на то, что будущее неизвестно (сема 1), русские паремии предписывают ожидать (сема 5) наступления позитивных событий и состояний (сема 11(+) + сема 2 + сема 10), что находит эмоциональное выражение в виде надежды на лучшее: Век живи, век надейся; Будет и на нашей улице праздник; Что бы ни случилось, всё клучшему; Слеза печали сменяется слезою радости; И крута гора, да забывчива, и лиха беда, да избывчива; И темна ночь, да не век ей быть; Заковал мороз реки, да не навеки; Не всё ненастье, выглянет и солнышко; После ненастья приходит и счастье; После ненастья вёдро бывает; После дождичка будет и солнышко; Взойдёт солнце и перед нашими воротами; Заглянет солнце и в наше оконце; Без надежды, что без одежды, и в тёплую погоду холодно; Лучше без одежды, чем без надежды и мн. др.

В паремиях находит выражение и сема 12 'судьба, участь': Om судьбы не уйдёшь; Суженого на коне не объедешь; Что было, то прошло, что будет, придёт; Чему быть, того не миновать; Будь, что будет. Такие пословицы и поговорки утверждают, что будущее предопределено, и предписывают человеку принимать его. Встречаются паремии, в которых под судьбой, участью (то, что определено точно) понимается смерть (сема 13): От своей смерти не уйдёшь; Прежде смерти не умрёшь; До веку не умрёшь; Живым в могилу не ляжешь; Кому повешену быть, тот не утонет; Человек родится для того, чтобы умереть.

Необходимо отметить, что русский паремический фонд располагает достаточно большим количеством пословиц и поговорок о смерти: Все люди смертны; Два века не проживёшь; Два века еще никто не жил на земле; Сколько ни живи, а умирать придётся; Сколько ни жить, а умирать не миновать; И то будет, что нас не будет; Придёт час, не будет и нас; Два раза не умирать, а однова не миновать; Сегодня умирать страшно, а когда-нибудь - ничего; Откуда пришли, туда и уйдём; Пришли из земли, в землю и ляжем; Все там будем: один раньше, другой позже; Смерть нашего брата не спросит, а придёт и скосит; Умереть да родить нельзя погодить и мн.др. Данные паремии утверждают, что смерть это единственное событие будущего, которое известно наверняка и которого нельзя избежать. Прескрипция, заключенная в этой группе паремий, обязывает человека принимать смерть как нежелательную, но неизбежную реалию жизни.

Сема 13 'смерть' может конкретизироваться в паремиях в виде идеи, что всё имеет свой конец: Всё имеет свой конец; Сколько цветку ни цвести, а быть опадать; Сколько кувшину по воду ни ходить, а голову сломить; Ничто не вечно под луной; Нет радости вечной, нет печали бесконечной; Весна да лето, пройдёт и не это; Как верёвочка ни вейся, а концу быть; Не на век и святая неделя; До поры, до времени. Как и в паремиях о смерти, паремии о конце чего-либо призывают смириться с таким ходом вещей. Их позитивная программа утверждает, что будущее способно 
сглаживать углы прошлого, трудности преходящи и, что бы ни случилось, в будущем это не будет иметь значения (сема 11(+)): Перемелется - все мука будет; Перекуётся - сварится; Обомнётся, оботрётся - все по-старому пойдёт. В сочетании с семой 6 'жизнь' сема 13(-) осмысляется как конец молодости, благоприятного периода жизни. Негативную оценку получает факт безвозвратно уходящего времени, забирающего у человека красоту и силу: Года, как вода, пройдут - не увидишь; Молодость пройдёт, как цветок отцветёт. Данная оценка трансформируется в прескрипцию, указывающую на необходимость жить сегодняшним днём, используя возможности настоящего момента: Живут один раз - не потом, а сейчас.

Сема 14(-) 'время, которое никогда не наступит, неопределённо далёкое будущее' реализуется в таких паремиях, как Сей день не без завтра (Седни не без заутрия); У завтра нет конца; Дней много, а все впереди; Впереди у Бога дней много; Дождёшься - на морковкино заговенье; Когда рак на горе свистнет; Дождёшься, когда солнце глиной залепят; Дождёшься после дождичка в четверг; Дождёшься на будущую осень лет через восемь. С помощью данной семы формируются поведенческие нормы, которые предписывают не полагаться на завтрашний день, жить в настоящем (Одно «нынче» лучше двух «завтра»), предпочитать доступное малое обещанному или возможному, но не гарантированному большему (Не сули журавля в небе, а дай хоть синицу, да в руки; Не сули бычка, дай чашку молочка; Не сули собаке пирога, а дай кусок хлеба; Синища в руке лучше журавля в небе), не откладывать выполнение своих обязательств на неопределённый срок (Соловья баснями не кормят; Завтраками не кормят; Не откладывай на завтра то, что можно сделать сегодня; Отклад не живёт богат).

Необходимо также отметить, что в русской лингвокультуре, по-видимому, не получили распространения пословицы, реализующие сему 15 'то, что можно готовить, создавать' и идею, что будущее является прямым следствием наших поступков в настоящем. Прескрипция, в основе которой лежит сема 15, указывает на необходимость принятия ответственности за будущее путем осознания его зависимости от настоящего по принципу «причина - следствие». Она обнаружена нами в трёх паремиях, две из которых имеют библейское происхождение: Что посеешь, то и пожнёшь; Посеешь ветер, пожнёшь бурю; Как потопаешь, так u полопаешь. На наш взгляд, такое малое количество пословиц свидетельствует о том, что в русской лингвокультуре причинно-следственная связь между настоящим и будущим не входит в число ценностных характеристик концепта «будущее». Действительно, сема 15 не встречается ни в одной из описанных выше смысловых паремических групп, поэтому будущее предстает существующим отдельно от настоящего, утрачивает связь с ним, перестает быть его следствием, по замечанию В. А. Масловой, «помещается где-то в неопределённом futurum» и «не соприкасается с настоящим» [10].

Подводя итоги анализу ценностно-нравственного компонента концепта «будущее», отметим, что основу поведенческих норм, формируемых связками сем, составляют две семы: сема 1 'то, что неизвестно, неопределённо' и сема 13 'смерть, конец чего-либо', причём ключевой, организующей вокруг себя основную массу прескрипций семой оказывается сема 1. Представления о том, что будущее неподконтрольно человеку, имеет в своей основе две идеи: зависимость мира и событий от воли выс- 
ших сил (сема 7) и предопределённость будущих событий (сема 12, сема 13). Действительно, как было замечено выше, исконно русские паремии не реализуют идею зависимости будущего от действий человека в настоящем и возможности формировать его лишь собственными усилиями (сема 15). Основная характеристика русского будущего - неизвестность, которая со временем проявит себя, т. е. станет видимым настоящим. Иными словами, русское будущее - это объективная реальность, которая ещё «не случилась».

\section{Обсуждение}

На наш взгляд, в результатах настоящего исследования можно проследить связь культурного концепта «будущее» с грамматическими значениями будущего времени в русском языке. Специфика будущего, связанная с его принципиальной ирреальностью, находит отражение в том, что в граммеме будущего времени, как правило, сочетаются грамматические значения темпоральности и субъективной модальности, однако в русском языке такое совмещение оказывается невозможным в силу видо-временной системы, в которой темпоральные показатели выступают также и в роли маркеров изъявительного наклонения, поэтому граммема будущего времени в русском языке в качестве обязательных передаёт значения вида и объективной модальности реальности, а значения субъективной модальности выражаются лексически и остаются опциональными. Согласно нашему предположению, необязательность категории субъективной модальности позволяет русскому сознанию избегать мыслить будущие события с точки зрения оценки их вероятности и отношения к ним субъекта, что косвенно подтвержается выявленными нами на основе концептуального анализа поведенческими нормами, отражающими эту сильную объективированность (независимость от субъекта) будущего.

С другой стороны, как показала С. Н. Глазкова [11], связь времени с грамматической модальностью, которая в русском языке почти не выражается с помощью личных форм глаголов, также оказывается условной. Анализируя этот вывод, А. А. Мёдова, в свою очередь, замечает, что время в русских модальных грамматических контекстах «либо не различается, либо имеет характер неконтролируемый, неопределённый, оно проходит само собой, без участия человека». По её мнению, «русский язык, по крайней мере, в области грамматической модальности, передаёт вовлечённость человека во время и одновременно безучастность к нему» [12, с. 143]. Эта мысль также соответствует сделанным нами выводам об объективированности будущего, сознательном отказе человека от воздействия на него и установке на принятие того, что случается помимо нашей воли, как ценностных доминантах концепта «будущее» в русской лингвокультуре.

Отметим, что результаты, полученные в ходе лингвокультурного концептуального анализа, могут найти применение и в смежных областях науки: когнитивной лингвистике, этнолингвистике, этнопсихолингвистике, культурологии и др. Особое значение, на наш взгляд, они будут иметь для сопоставительного лингвострановедения, занимающегося изучением феномена сознания в аспекте обучения русскому языку как иностранному [13]. Это обусловлено тем, что, по замечанию А. С. Мамонтова, «первоочередной задачей [сопоставительного лингвострановедения] является 
выделение принципов отбора и минимизации коммуникативно-значимого материала с позиции учёта родной культуры адресата, поскольку содержание обучения в аспекте формирования соответствующей компетенции будет различаться в зависимости от того, к какой именно культуре принадлежит тот или иной обучающийся» $[14$, c. 156$]$.

\section{Ссылки / References}

1. Логический анализ языка. Язык и время / Отв. ред. Н. Д. Арутюнова, Т. Е. Янко. М.: Индрик, 1997. 352 с.

2. Михеева Л. Н. Время в русской языковой картине мира. Иваново: Иван. гос. ун-т, 2003. 252 c.

3. Обухова Т. А. Вербализация концепта «время» во французском и русском языках: лингвокультурный аспект : на материале лексических единиц и свободных словосочетаний : дисс. ... канд. филол. наук. Челябинск, 2011. 175 с.

4. Лазуткина Е. М. Оценки будущего в предложении и тексте // Логический анализ языка. Лингвофутуризм. Взгляд языка в будущее / Н. Д. Арутюнова (ред.). М., 2011. С. 210-219.

5. Карасик В. И. Языковой круг: личность, концепты, дискурс. Волгоград: Перемена, 2002. $331 \mathrm{c}$.

6. Сорокин П. А. Человек, цивилизация, общество / Общ. ред., сост. и предисл.

А. Ю. Союмонов: Пер. с англ. М., 1992.

7. Корнилов О. А. Языковые картины мира как производные национальных менталитетов. 2-е изд., испр. и доп. М.: ЧеРо, 2003. 349 с.

8. Словарь-тезаурус русских пословиц, поговорок и метких выражений / В. И. Зимин. М.: АСТ-ПРЕСС КНИГА, 2016. 736 с.

9. Зализняк А. А., Левонтина И. Б., Шмелёв А. Д. Ключевые идеи русской языковой картины мира. М.: Языки славянской культуры, 2005. 544 с.

10. Маслова В. А. Введение в когнитивную лингвистику: Учебное пособие. URL:

https://bookshake.net/r/vvedenie-v-kognitivnuyu-lingvistiku-valentina-avraamovna-maslova (дата обращения: 04.10.2019).

11. Глазкова С. Н. Модальная языковая картина мира русских // Россия и Запад: диалог культур. 2013. № 2. URL: http://www.regionalstudies.ru/journal/homejornal/rubric/201211-02-22-15-01/273---q----q.html (дата обращения: 15.03.2020).

12. Мёдова А. А. Сознание в модусе времени. M.: NOTA BENE, 2014. 220 c.

13. Мамонтов А. С., Богуславская В. В., Гусман Т. Р. Феномен сознания в аспекте теории и практики обучения иностранному языку как средству межкультурной коммуникации // Изучение и преподавание русского языка в разных лингвокультурных средах. Сборник статей Международной научно-практической конференции молодых учёных. Москва, РУДН, 23-24 сентября 2019 г. М., 2019. С. 51-75.

14. Мамонтов А. С. Сопоставительное лингвострановедение и обучение иностранным языкам // Язык и культура в филологическом вузе. Актуальные проблемы изучения и преподавания : сб. научных трудов. М., 2006. С. 155-163. 